\title{
IDENTIFIKASI SERANGGA PERUSAK DAN TINGKAT KERUSAKAN PADA BIBIT MAHONI (Swietenia macrophyla King) DI AREAL PERSEMAIAN PERMANEN BPDASHL KAPUAS PONTIANAK
}

\author{
(Identification Of Deteriorating Insects And The Level Of Damage To Mahogany Seedlings \\ (Swietenia Macrophyla King) In The Bpdashl Kapuas Permanent Nursery In Pontianak)
}

\section{Riona, Rosa Suryantini, Ratna Herawatiningsih}

Fakultas Kehutanan Universitas Tanjungpura Pontianak. Jl. Daya Nasional Pontianak 78124 Email: ona.riona93@gmail.com

\begin{abstract}
Mahogany (Swietenia macrophyla King) is a wood plant that has the potential to be developed in plantations. One of the factors that interfered in the development of mahogany was destructive insects. This study aimed to identify the species of destructive insects and calculate the level of damage to mahogany seedlings in the permanent nursery BPDASHL Kapuas Pontianak conducted by the survey method. Collecting insects on mahogany seedlings is identified by using insect nets and catching them directly by hand. Calculation of damage level is to use the criteria table and crop assessment category. The results showed that there were 4 species of insects which damaged the seedlings of mahogany in the nursery, namely Valanga nigricornis, Tagasta marginella, Anoplolepis longipes and Xyloxandrus sp. The number of seeds attacked as many 585 seeds from 2.176 seeds, with the level of damage to the entire pathway which is $12,39 \%$ and included in the category of minor damage.
\end{abstract}

Keywords: Destructive insects, Identification, level of damage, mahogany seedlings, permanent nursery

\section{PENDAHULUAN}

Salah satu jenis yang potensial untuk pengembangan hutan tanaman adalah tanaman mahoni (Swietenia macrophyla King), karena jenis ini kayunya dapat digunakan sebagai bahan baku industri kehutanan seperti industri vinir, kayu lapis, bangunan rumah, dan produksi kayu lainnya seperti kerajinan tangan. Mahoni juga memiliki karakteristik kayu dengan warna dan penampakan serat yang indah sehingga bernilai ekonomis tinggi (Mindawati dan Megawati 2013).

Salah satu organisme perusak yang menjadi hama adalah ordo serangga (insect), dikarenakan serangga adalah salah satu hewan yang memiliki populasi yang sangat cepat berkembang. Sebagai salah satu komponen dalam ekosistem, serangga tidak selalu bernilai negatif (sebagai perusak) tetapi juga memiliki fungsi positif seperti agen polinasi. Serangga perusak adalah serangga yang menyebabkan kerusakan secara fisiologis dan ekologis bagi tanaman sehingga dapat mengganggu dan menghambat suatu perkembangan tanaman (Wikardi dan Wahyono 1991). Jika kerusakan yang disebabkan oleh serangga dapat menimbulkan kerugian ekonomi bagi manusia, maka serangga tersebut dikatakan sebagai hama (Sianipar et al. 2015).

Faktor yang menjadi masalah pada penelitian ini adalah bibit yang dihasilkan oleh persemaian permanen BPDASHL 
untuk kesehatannya belum menjamin, maka ketika bibit mahoni ataupun bibit yang lainnya pada saat di persemaian terserang oleh serangga hama atau penyakit dan ketika disalurkan ke berbagai daerah bibit tersebut membawa serangga hama atau penyakit, maka tidak menutup kemungkinan serangga hama atau penyakit yang terbawa akan menular atau menyerang kepada tanaman lain yang ditanam secara bersama. Oleh karena itu sangat perlu penanganan yang baik terhadap serangga hama pada persemaian ini. Salah satu cara pertama untuk penanganan yaitu mengetahui jenis-jenis serangga perusak yang berpotensi menjadi hama bagi bibit dan juga mengetahui sudah seberapa tingkat kerusakan yang terjadi pada bibit mahoni, agar pemeliharaan kedepannya lebih ditingkatkan lagi. Hal ini bertujuan supaya bibit mahoni yang akan disalurkan sudah terjamin kesehatannya dan aman ditanam pada lahan penanaman. Penelitian juga dilakukan mengingat belum ada data jenis serangga perusak dan tingkat kerusakan pada bibit mahoni di persemaian permanen BPDASHL Kapuas Pontianak.

Penelitian bertujuan untuk mengidentifikasi jenis serangga perusak dan menghitung tingkat kerusakan yang terjadi pada bibit mahoni di persemaian permanen BPDASHL Kapuas Pontianak. Hasil penelitian ini diharapkan dapat memberikan informasi mengenai jenisjenis serangga perusak yang ditemukan di areal persemaian mahoni serta memberikan informasi mengenai seberapa tingkat kerusakkan yang terjadi pada bibit mahoni, sehingga pihak persemaian dapat melakukan pemeliharaan dan perlindungan yang tepat.

\section{METODE PENELITIAN}

Penelitian ini dilaksanakan di areal persemaian permanen BPDASHL Kapuas Pontianak selama 2 minggu di lapangan, terhitung sejak tanggal 9 sampai 24 November 2018. Alat dan bahan yaitu pinset, jaring serangga, suntikan, kantong plastik, termohigrometer, kamera dan kaca pembesar. Sedangkan objek yang diamati adalah bibit mahoni dan serangga perusak. Pengambilan data dilakukan dengan metode survey, melalui: 1) penentuan tanaman sampel di buat secara sistematis yaitu di tentukan dengan sengaja. Jumlah jalur yang diamati yaitu 6 jalur dan setiap jalur diambil sampel bibit mahoni sebanyak $10 \%$ dari total bibit mahoni per jalur (Sakdiah et al. 2015); 2) menangkap serangga perusak dengan jaring serangga dan juga menggunakan tangan serta mengidentifikasi serangga menggunakan buku identifikasi karangan Raharjo (2017) dan (Robinson 2005); 3) menghitung persentase serangan dan tingkat kerusakan menggunakan kriteria (Tabel 1). 
Tabel 1. Kriteria dan kategori penilaian tanaman akibat serangan serangga perusak berdasarkan tipe kerusakan yang tampak. (Plant assessment criteria and categories due to destructive insect attacks based on the type og damage seen)

\begin{tabular}{clc}
\hline Skor & \multicolumn{1}{c}{ Tanda Kerusakan } & Kategori \\
\hline 0 & $\begin{array}{l}\text { Pertumbuhan baik, daun hijau, sehat dan segar, } \\
\text { beberapa daun hilang dari pangkal batang. }\end{array}$ & Sehat \\
1 & $\begin{array}{l}\text { Bagian tanaman daun berlubang, menggulung, melipat, } \\
\text { batang berlubang dan mengelupas 1\%-25\%. }\end{array}$ & Ringan \\
2 & $\begin{array}{l}\text { Daunnya menggulung melipat, menggulung berlubang, } \\
\text { dan kerusakan tersebut sampai ke bagian pucuk } \\
\text { sehingga daun menguning }>25 \%-50 \%\end{array}$ & Sedang \\
& $\begin{array}{l}\text { Tanaman rusak berat, dimana lebih dari setengah } \\
\text { tanaman patah, gundul, leher akar terpotong, sehingga } \\
\text { tumbang hampir mati }>50 \%-100 \% .\end{array}$ & Berat \\
\end{tabular}

Sumber: Diektorat perlindungan tanaman pangan 2000

Serangga yang terkumpul diidentifikasi dengan buku identifasi karangan Raharjo (2017) dan Robinson (2005), kemudian dianalisis dengan menghitung persentase tanaman terserang dengan rumus:

a) Perhitungan persentase

$$
\mathrm{P}=\frac{\alpha}{N} \times 100 \%
$$

Dimana:

$\mathrm{P}=$ persentase tanaman terserang $\alpha=$ Jumlah tanaman yang terserang

$\mathrm{N}=$ Jumlah tanaman yang diamati

b) Tingkat kerusakan pada tiap jalur

$$
\mathrm{I}=\frac{\sum(n i x V i)}{Z N} x 100 \%
$$

Keterangan:

$\mathrm{I}=$ Tingkat kerusakan pada setiap jalur

$\mathrm{N}=$ Jumlah tanaman pada setiap jalur

ni $=$ Jumlah tanaman berdasarkan

kriteria serangan
$\mathrm{Vi}=$ Nilai kriteria untuk serangan hama $\mathrm{Z}=$ Nilai tertinggi kriteria serangan hama

c) Tingkat kerusakan seluruh jalur

$$
\mathrm{Y}=\frac{\sum I}{N}
$$

Keterangan:

$\mathrm{Y}=$ Tingkat kerusakan seluruh

$\mathrm{I}=$ Tingkat kerusakan tiap jalur

$\mathrm{N}=$ Jumlah jalur.

\section{HASIL DAN PEMBAHASAN}

Hasil identifikasi dan pengamatan langsung di lapangan terhadap bibit mahoni ditemukan 4 jenis serangga perusak yaitu belalang kayu, belalang kerucut, semut gramang dan penggerek batang. Secara lengkap hasil identifikasi serangga perusak yaitu (Tabel 2). 
Tabel 2. Jenis Serangga Perusak yang Menyerang Tanaman Mahoni di Persemaian. (A type of destructive insect that attacks the mahogany in the nursery)

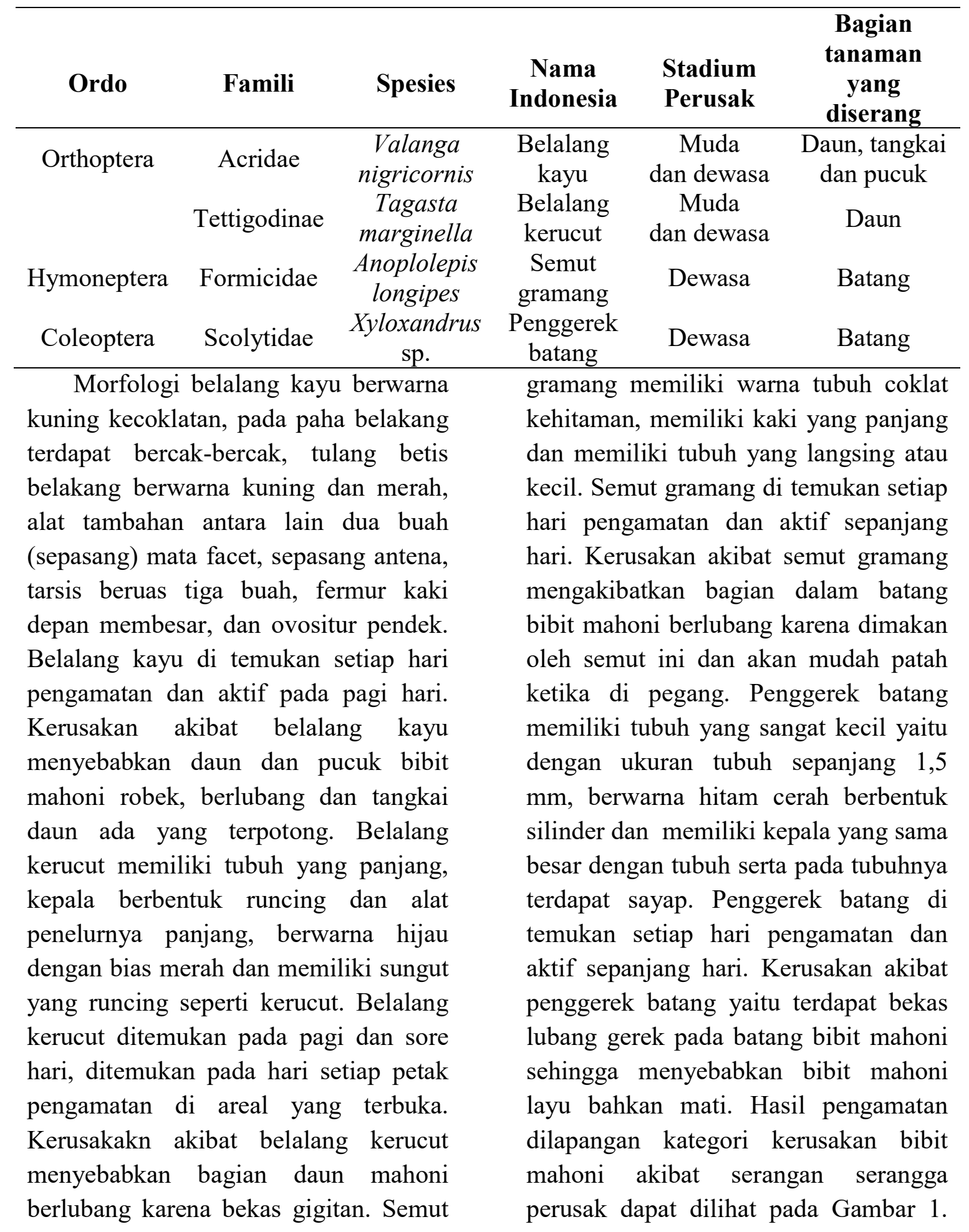




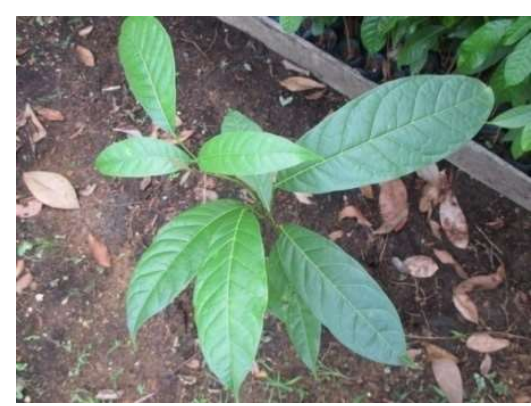

a

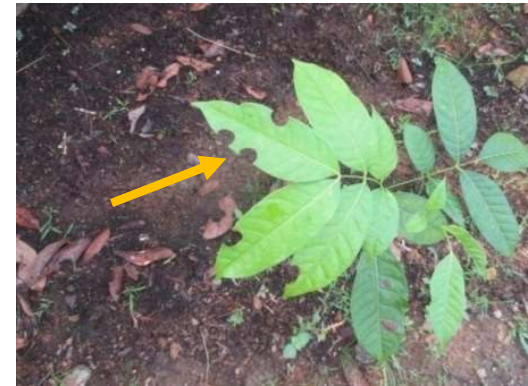

b

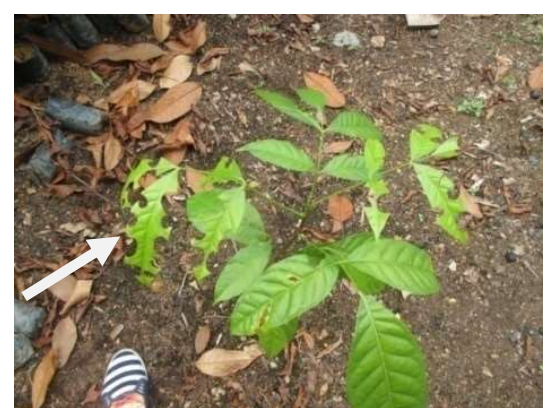

c
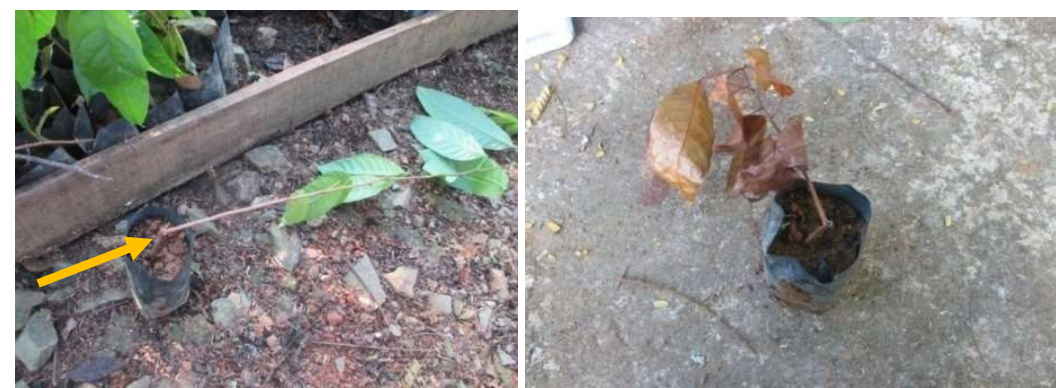

d

Gambar 1. Kategori Kerusakan Bibit Mahoni Akibat Serangga Perusak: (a) tanaman sehat, (b) serangan ringan, (c) serangan sedang, (d) serangan berat. (category og damage to mahogany seedlings due to destructive insects (a) healthy plants, (b) minor attack, (c) moderate attack, (d) severe attack).

Kriteria dan kategori tanaman mahoni yang terserang oleh serangga perusak berdasarkan penilaian tabel dari Direktorat Perlindungan tanaman pangan (2000) dan hasil pengamatan di lapangan antara lain: (a) Kategori sehat yaitu daun hijau, sehat dan segar. (b) Kategori rusak ringan yaitu bagian tepi daun rusak sedikit dan tidak seluruh daun yang mengalami kerusakan. (c) Kategori kusak sedang yaitu bagian daun dalam satu tangkai yang mengalami kerusakan cukup banyak. (d) Kategori rusak berat yaitu bagian batang bibit mudah sekali patah ketika di pegang atau ditiup angin dan batang bibit mengalami kelayuan, kemudian kering dan mati.

Perhitungan tanaman yang mengalami kerusakan pada setiap jalur dan pengamatan di lapangan menunjukan bahwa adanya tanaman mahoni yang terserang oleh serangga perusak (Tabel 3). 
Tabel 3. Persentase Kerusakan Akibat Serangga Perusak. (Percentage damage due to destructive insects).

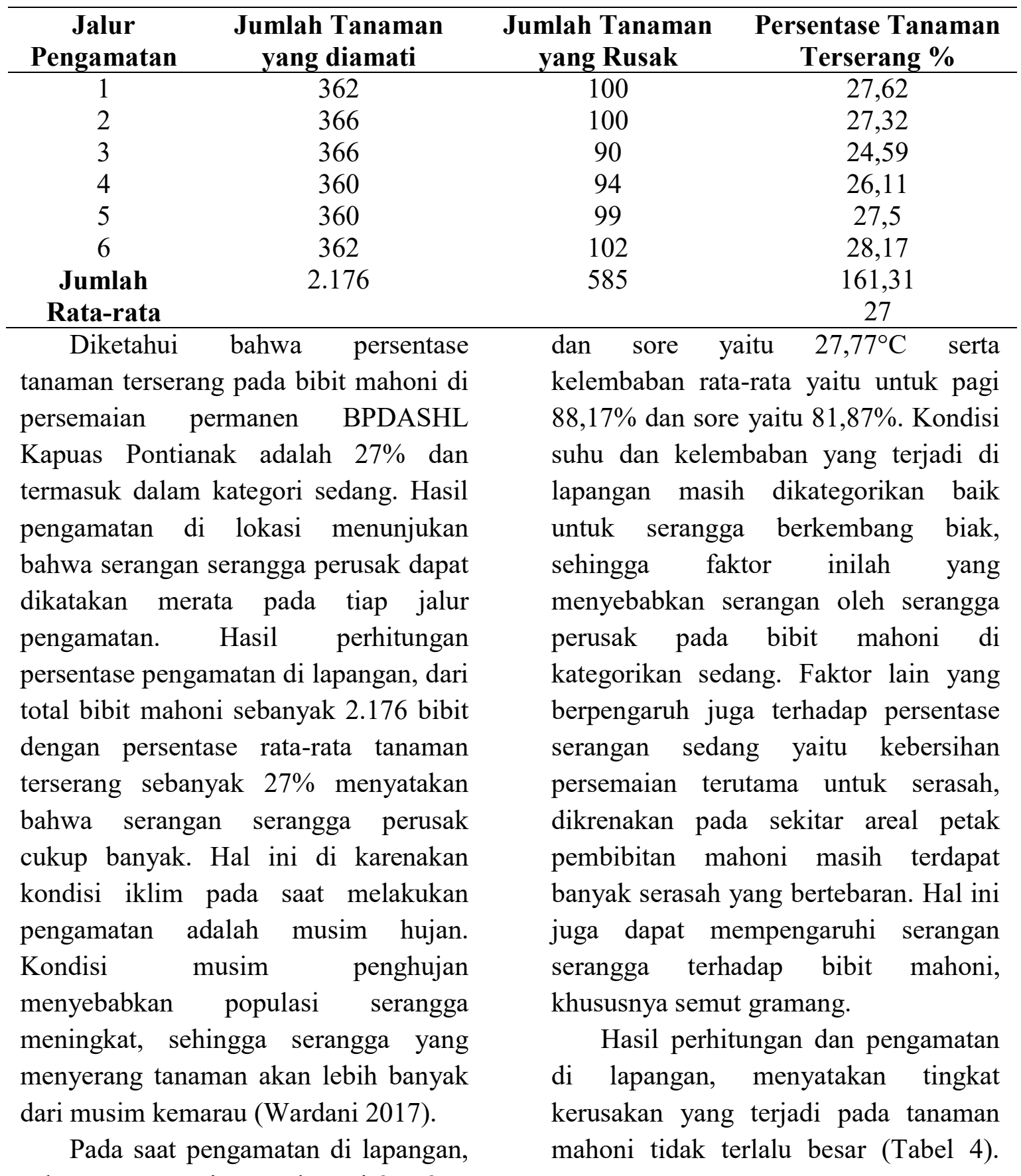


Tabel 4. Tingkat Kerusakan Tiap Jalur. (Level of damage in a line).

\begin{tabular}{cccc}
\hline $\begin{array}{c}\text { Jalur } \\
\text { Pengamatan }\end{array}$ & $\begin{array}{c}\text { Jumlah Tanaman } \\
\text { Yang diamati }\end{array}$ & $\begin{array}{c}\text { Tingkat } \\
\text { Kerusakan }(\%)\end{array}$ & $\begin{array}{c}\text { Kategori Tingkat } \\
\text { Rusak }\end{array}$ \\
\hline 1 & 362 & 14,36 & Ringan \\
2 & 366 & 12,75 & Ringan \\
3 & 366 & 10,92 & Ringan \\
4 & 360 & 11,38 & Ringan \\
5 & 360 & 12,5 & Ringan \\
6 & 362 & 12,43 & Ringan \\
Jumlah & 2.176 & 74,38 & Ringan \\
Rata-rata & & 12,39 & Selan \\
\hline
\end{tabular}

Kategori kerusakan yang terjadi pada setiap jalur pengamatan berkisar antara $10,92 \%$ sampai dengan $14,36 \%$. Tingkat kerusakan tanaman rata-rata seluruh jalur yaitu $12,39 \%$ termasuk dalam kategor ringan. Hal ini dikarenakan adanya kegiatan perawatan oleh tenaga kerja berupa pemeliharaan tanaman yang intensif terutama dilakukanya penyemprotan insektisida dan pembersihan gulma di sekitar jalur. Pemeliharaan ini dilakukan untuk menghindari kerusakan yang lebih berat dan untuk mengurangi populasi serangga. Pendapat Roshetko et al. (2015) juga mengatakan pemeliharaan bibit sangat perlu dilakukan, seperti penyiangan bibit dan keragaman jenis bibit yang ditanam.

Faktor lain juga yang menyebabkan ringannya kerusakan yang terjadi di persemaian adalah adanya saingan makanan. Dimana disekitar petak pengamatan terdapat jenis-jenis bibit yang lain yang dapat mengalihkan serangan bagi serangga perusak. Sehingga serangga perusak tidak hanya makan atau menyerang tanaman mahoni saja tetapi juga berbagi dengan tanaman yang ada disekitar jalur pengamatan. Selain karena perawatan dan faktor saingan makanan, ada juga faktor yang mempengaruhi tingkat kerusakan pada bibit mahoni ringan yaitu kategori serangan yang disebabkan oleh serangga perusak di lapangan banyak yang menunjukan kategori ringan.

Persentase terserangnya bibit mahoni yaitu $27 \%$ dan termasuk kedalam kategori sedang serta tingkat kerusakan yang terjadi yaitu $12,39 \%$ dan termasuk kedalam kategori ringan. Hal ini dapat disimpulkan bahwa kondisi bibit mahoni di persemaian permanen BPDASHL Kapuas Pontianak masih dalam kategori baik dan ringan karena tingkat rusaknya bibit mahoni dikategorikan ringan saja. Akan tetapi pemeliharaan terhadap serangga perusak tetap harus ditingkatkan. Hal ini penting dilakukan agar kedepannya tidak terjadi ledakan serangan serangga perusak terhadap bibit yang ada di persemaian ini.

\section{KESIMPULAN DAN SARAN}

Ditemukan 4 jenis serangga perusak bibit mahoni di persemaian yang terdiri dari 3 Ordo, 4 Famili yaitu belalang kayu (Valanga nigricornis) dari ordo 
Orthoptera; famili Acrididae, belalang kerucut (Tagasta marginella) dari ordo Orthoptera; famili Tettigodinae, semut gramang (Anoplolepis longipes) dari ordo Hymoneptera; famili Formicidae dan penggerek batang (Xyloxandrus sp.) dari ordo Coleoptera; famili Scolytidae. Persentase tanaman mahoni terserang oleh serangga perusak yaitu $27 \%$ termasuk ke dalam kategori sedang. Tingkat kerusakan seluruh jalur pada bibit mahoni akibat serangan serangga perusak adalah 12,39\% dan termasuk dalam kategori ringan.

Serangan serangga perusak pada bibit mahoni di persemaian permanen BPDASHL Kapuas Pontianak masih dalam kondisi yang ringan, namun proses pemeliharaan tetap harus ditingkatkan agar kedepannya tidak terjadi ledakan serangan serangga terhadap bibit yang ada di persemaian. Pembersihan serasah pada sekitar petak bibit harus dilakukan agar tidak mengundang serangga perusak menyerang bibit. Penyemprotan insektisida juga harus disemprot kebagian batang bibit mahoni, agar serangga perusak yang merusak batang bibit juga dapat diatasi. Selain itu pemasangan paranet pada petak pembibitan juga harus dilakukan, agar serangga perusak tidak mudah masuk dan merusak bibit.

\section{DAFTAR PUSTAKA}

Direktorat Perlindungan Tanaman Pangan. 2000. Pedoman Pengamatan dan Pelaporan Perlindungan Tanaman Pangan. Jakarta: Direktorat Perlindungan Tanaman Pangan.

Mindawati N, Megawati. 2013. Manual Budidaya Mahoni (Swietenia macrophyla. King). Pusat Penelitian dan Pengembangan Peningkatan Produktivitas Hutan, Badan Penelitian dan Pengembangan Kehutanan. Bogor www.fordamof.org/content/publikasi/post/268. (diakses pada 21 Juli 2018).

Raharjo AA. 2017. Hama dan Penyakit Tanaman. Depok: PT.Trubus Swadaya.

Robinson. 2005. Urban Insects and Arachnids. New Tork: Cambridge University Press.

Roshetko JM, Sebastian GE, Tolentino, Jr El, Carandang WM, Bertomeu M, Tabdaba A,Yao CE. 2015. Buku Acuan Pembibitan Pohon. Bogor: World Agroforestry Centre.

Sakdiah TH, Herwina H, Mairawita. 2015. Intensitas serangan semut pada tanaman buah naga (Hylocereus sp.) di kota Pariaman, Sumatera Barat. Jurnal Biologi. 4: 242-247.

Sianipar SM, Djaya L, Simarmata PD. 2015. Keragaman dan kelimpahan serangga hama tanaman padi (Oryza satival.) di dataran rendah jatisari, Karawang, Jawa Barat. Jurnal Agrin. 19: 89-96.

Wardani N. 2017. Perubahan Iklim dan Pengaruhnya Terhadap Serangga Hama. Prosiding Seminar Nasional Agroinovasi Spesifik Lokasi Untuk Ketahanan Pangan pada Era Masyarakat Ekonomi ASEAN. http://lamping.litbang.pertanian.go.i $\mathrm{d} /$ ind/images/stories/publikasi/prosid ing_1_2017/95.seminarlampungnila 
JURNAL HUTAN LESTARI (2019)

Vol. 7 (1) : $424-432$

2.pdf (diakses pada 11 Desember 2018).

Wikardi AE, Wahyono ET. 1991.

Serangga-serangga perusak pada tanaman kayu manis (Cinnamomum sp.) dan musuh alaminya. Buletin

Litro. 6 : 20-26. 